\title{
PENGEMBANGAN MEDIA PEMBELAJARAN MATEMATIKA SMP UNTUK MENGONSTRUKSI VOLUME BANGUN RUANG
}

\author{
Syofni \\ Pendidikan Matematika, Universitas Riau \\ Email : syofnimath@yahoo.com
}

\begin{abstract}
This research is the development research, which aims to develop a formula for constructing props volume beams and tubes that can be used in primary and secondary education levels. This research has resulted 1) A set of props to construct formulas accompanied beam volume usage procedures, 2) A set of props to construct the volume of the tube with the procedures used. The process begins with the development of props issue of lack of teachers ability (participants PLPG 2013) to describes the process of formation of the volume formula beams and tube, then researchers design and make the props, then performed the validation and testing. The results of the validation state that props valid for use in primary and secondary education level.
\end{abstract}

Keywords : Development, Viewer tool, Beams, Tubes, Creativity

\section{PENDAHULUAN}

Matematika merupakan ilmu dasar yang sangat besar pengaruhnya terhadap penguasaan ilmu pengetahuan dan teknologi. Matematika memegang peranan penting dalam pendidikan, karena matematika memberikan peluang untuk terbentuknya berfikir, berkomunikasi, bernalar, secara sistematis dan logis. Tujuan pembelajaran matematika secara nasional menggambarkan pentingnya pelajaran matematika mulai dari sekolah dasar sampai sekolah menengah, sebagaimana yang tercantum dalam kurikulum KTSP 2006 yaitu : (1) melatih cara berfikir dan bernalar dalam menarik kesimpulan, (2) mengembangkan aktivitas kreatif yang melibatkan imajinasi, intuisi, dan penemuan dengan mengembangkan pemikiran orisinil, rasa ingin tahu, membuat prediksi dan dugaan, srta mencoba-coba, (3) mengembangkan kemampuan pemecahan masalah, (4) mengembangkan kemampuan menyampaikan informasi atau mengkomunikasikan gagasan (BNSP, 2006)

Tujuan pembelajaran matematika tersebut, memberi makna bahwa pembelajaran matematika dapat dijadikan sebagai sarana untuk malatih siswa dan mengembangkan kemampuan menarik kesimpulan, membentuk kreatifitas, kemampuan memecahkan masalah, dan mengkomunikasikan gagasan, serta menata cara berfikir dan pembentukan keterampilan matematika untuk mengubah tingkah laku siswa. Perubahan tingkah laku siswa akan terlihat pada akhir proses pembelajaran yang dinyatakan dalam hasil belajar.

Dalam pembelajaran, siswa didorong untuk menemukan sendiri dan mentranformasikan informasi kompleks, mengecek informasi baru dengan yang sudah ada dalam ingatannya dan melakukan pengembangan menjadi informasi atau kemampuan yang sesuai dengan lingkungan dan zaman tempat dan waktu ia hidup (Permendikbud No. 81A Tahun 2013).Dalam matematika objek dasar yang dipelajari bersifat abstrak, atau disebut juga objek mental. Objek matematika itu adalah objek pikiran. Objek dasar matematika meliputi fakta, konsep, operasi atau relasi dan prinsip. Berdasarkan objek-objek matematika ini disusun suatu pola dan struktur matematika.

Berdasarkan tujuan pembelajaran matematika dan objek dasar matematika yang bersifat abstrak dipandang sangat perlu untuk menyampaikan materi pembelajaran matematika menggunakan media (alat peraga) agar menjadi kongkrit dan dapat diterima siswa dengan baik.

Soedjadi (2000) mengemukakan bahwa sampai saat ini masih saja terdengar (mungkin atau selalu?) tentang sukarnya siswa menguasai matematika. Keluhan ini bukan hanya di jenjang SD sampai SLTA, namun juga pada jenjang pendidikan yang lebih tinggi. Sukarnya siswa dalam menyerap atau menguasai materi matematika tentu dipengaruhi oleh berbagai faktor. 
Pengalaman peneliti sebagai dosen Program Studi Pendidikan Matematika yang mahasiswanya bukan saja mahasiswa regular (asal SMA) tetapi juga guru-guru mulai dari tingkat sekolah dasar sampai sekolah menengah atas, hampir $90 \%$ mahasiswa mengalami kesulitan/ tidak memahami proses pembentukan atau penemuan formula (rumus) untuk menghitung volume balok, tabung dan lain-lain. Mahasiswa atau guru hanya hafal rumus, dan tidak memahami arti dari satuan ukuran. Hal yang sama juga terjadi untuk guruguru peserta PLPG, yang bila ditanya mengapa rumusnya seperti itu, jawabannya sama, yaitu seperti itu yang ada di buku, tanpa ada penjelasan tentang prosedur yang logis dan masuk akal.

Berdasarkan kondisi di atas, peneliti merasa terpanggil untuk mengembangkan media pembelajaran (alat peraga) yang membantu untuk mengkonstruksi formula volume balok dan tabung. Dengan media ini siswa/guru akan mampu membedakan satuan panjang, luas dan volume (isi) dan mampu mengembangkan yang bermakna logis (masuk akal).

Penelitian ini perlu dilakukan, karena dari hasil penelitian ini nanti akan memberikan bantuan pada guru dan siswa sekolah menengah untuk menemukan rumus Volume Balok dan Tabung secara lebih bermakna, logis dan masuk akal, yang sebelumnya guru dan siswa hanya menghafal rumus tanpa makna.

Alat peraga sebagai media pembelajaran diambil dari kata media berasal dari bahasa latin, yakni medius yang secara harfiah berarti tengah, pengantar, atau media. Media pembelajaran dapat dipahami sebagai segala sesuatu yang dapat menyampaikan dan menyalurkan pesan dari sumber sacra terencana sehingga tercipta lingkungan belajar yang kondusif dimana penerimanya dapt melakukan proses belajar secara efisien dan efektif. Dengan demikian tujuan pemanfaatan media dalam proses pembelajaran adalah untuk mengefektifkan dan mengefisiensikan proses pembelajaran itu sendiri (Munadi, 2012)

Pemakaian media pembelajaran dalam proses belajar mengajar dapat membangkitkan keinginan dan minat yang baru, membangkitkan motivasi dan rangsangan kegiatan belajar bahkan membawa pengaruhpengaruh psikologis terhadap siswa. Penggunana media pembelajaran pada tahap orientasi pengajaran yang akan sangat membantu mengefektifkan proses pembelajaran dan penyampaian pesan dan isi pembelajaran pada saat itu. Di samping membangkitkan motivasi dan minat siswa, media pembelajaran juga dapat membantu siswa meningkatakan pemahaman, menyajikan data yang menarik dan terpercaya, memudahkan menafsirkan dan memadatkan informasi (Djamarah, 2002).

Dengan demikian, media pembelajaran adalah segala sesuatu yang dapat digunakan untuk menyalurkan bahan pembelajaran sehingga dapat merangsang perhatian, minat, pikiran, dan perasaan penbelajar (siswa) dalam kegiatan belajar untuk mencapai tujuan pembelajaran tertentu.(Konsorsim, 2013). Sudjana (2004), menyatakan bahwa setiap pembelajaran ditandai dengan empat unsur yang tidak dapat dilepas dari unsure lainnya, yaitu tujuan, bahan/materi, metode dan alat.

Matematika merupakan disiplin ilmu yang mempunyai sifat khas bila dibandingkan dengan disiplin ilmu yang lain. Secara singkat dikatakan bahwa matematika berkenaan dengan ide-ide atau konsep-konseo abstrak yang tersusun secara hirarkis dan penalarannya deduktif. Hal yang demikian tentu akan membawa akibat pada terjadinya proses pembelajaran matematika. Menurut Dienes (dalam Hudoyo, 1988) dikatakan bahwa setiap konsep atau prinsip matematika dapat dimengerti secara sempurna hanya jika pertama-tama disajikan kepada peserta didik dalam bentuk-bentuk kongkrit. Dengan demikian dapatlah dikatakan bahwa betapa pentingnya penggunaan media (termasuk alat peraga) dalam pembelajaran matematika dan alat harus disesuiakan dengan tahap berpikir siswa

Dienis (dalam Hudoyo, 1998) berpendapat bahwa setiap konsep atau prinsip matematika dapat dimengerti secara sempurna hanya jika pertama-tama disajikan kepada peserta didik dalam bentuk konkrit. Sehingga dapatlah dimengerti bahwa dienes menekan betapa pentingnya memanipulasi obyek-obyek dalam pembelajaran matematika. 
Selain mempersiapkan langkah-langkah penggunaan alat peraga, seperti persiapan guru, lingkungan, persiapan peserta didik, maka perlu pula mengetahui prinsip-prinsip umum dalam penggunaan alat peraga, di antaranya sebagai berikut.

1. Penggunaan alat peraga hendaknya sesuai dengan tujuan pembelajaran.

2. Alat peraga yang digunakan hendaknya sesuai dengan metode/strategi pembelajaran.

3. Tidak ada satu alat peragapun yang dapat atau sesuai untuk segala macam kegiatan belajar.

4. Guru harus terampil menggunakan alat peraga dalam pembelajaran.

5. Peraga yang digunakan harus sesuai dengan kemampuan siswa dan gaya belajarnya.

6. Pemilihan alat peraga harus obyektif, tidak didasarkan kepada kesenangan pribadi.

7. Keberhasilan penggunaan alat peraga juga dipengaruhi oleh kondisi lingkungan.

Menurut E.T. Ruseffendi (dalam Pujiati, 2009a) ada beberapa persyaratan yang harus dimiliki alat peraga agar fungsi atau manfaat dari alat peraga tersebut sesuai dengan yang diharapkan dalam pembelajaran.

1. Sesuai dengan konsep matematika.

2. Dapat memperjelas konsep matematika, baik dalam bentuk real, gambar atau diagram dan bukan sebaliknya (mempersulit pemahaman konsep matematika)

3. Tahan lama (dibuat dari bahan-bahan yang cukup kuat).

4. Bentuk dan warnanya menarik.

5. Dari bahan yang aman bagi kesehatan peserta didik.

6. Sederhana dan mudah dikelola.

7. Ukuran sesuai atau seimbang dengan ukuran fisik dari peserta didik.

8. Peragan diharapkan menjadi dasar bagi tumbuhnya konsep berpikir abstrak bagi peserta didik, karena alat peraga tersebut dapat dimanipulasi (dapat diraba, dipegang, dipindahkan, dipasangkan, dan sebagainya) agar peserta didik dapat belajar secara aktif baik secara individual maupun kelompok.

Menurut Pujiati (2009a) pemilihan alat peraga yang tepat dan digunakan secara benar diharapkan dapat:

1. Mempermudah abstraksi,

2. Memudahkan, memperbaiki, atau meningkatkan penguasaan konsep atau fakta,

3. Memberikan motivasi,

4. Memberikan variasi pembelajaran,

5. Meningkatkan efisiensi waktu,

6. Menunjang kegiatan matematika di luar kelas yang menunjukkan penerapan matematika pada peristiwa nyata, dan

7. Meningkatkan keterlibatan peserta didik dalam pembelajaran.

Pada alat peraga ini perlu dilakukan pengujian atau validitas. Menurut Azwar (1986) dalam Matondang (2009) validitas berasal dari kata validity yang mempunyai arti sejauh mana ketepatan dan kecermatan suatu alat ukur dalam melakukan fungsi ukurnya. Menurut Sudijono (2009) validitas adalah suatu ukuran yang menunjukkan tingkat kesahihan suatu tes. Menurut Nursalam (2003) dalam Matondang (2009) validitas adalah suatu ukuran yang menunjukkan tingkat kevalidan atau kesahihan suatu instrumen.

Dari beberapa penjelasan diatas, dalam kaitannya dengan media, peneliti menyimpulkan validitas adalah tingkat kevalidan atau kesahihan suatu media. Untuk memperoleh validitas media ini perlu dilakukan pengujian yang disebut uji validitas atau validasi.

Sugiyono (2008) mengemukakan bahwa ada 3 cara pengujian validitas yaitu: (1) Pengujian validitas konstruksi, pengujian ini dilakukan dengan menggunakan pendapat para ahli (judgement expert); (2) Pengujian validitas isi, pengujian ini dilakukan dengan membandingkan antara isi instrumen dengan materi pelajaran yang telah diajarkan; (3) Pengujian validitas external, pengujian ini dilakukan dengan cara membandingkan antara kriteria yang ada pada instrumen dengan faktafakta empiris yang terjadi dilapangan. Pada pengembangan media ini pengujian validitas yang dilakukan adalah pengujian validitas konstruksi menggunakan pendapat para ahli (judgement expert). 
Berdasarkan hal-hal tersebut di atas dapatlah ditarik suatu kesimpulan bahwa dalam belajar matematika, pengalaman belajar siswa sangatlah penting. Pengalaman tersebut akan membentuk suatu pemahaman apabila ditunjang dengan bantu belajar, yang berfungsi mengkonkretkan materi-materi matematika yang bersifat abstrak. Dengan demikian alat bantu belajar bisa disebut media yang berfungsi dengan baik apabila media tersebut dapat memberikan pengalaman belajar yang bermakna, mangaktifkan dan menyenangkan siswa.

Dengan menggunakan alat peraga kongkrit yang merupakan alat ukur volume balok dan tabung yang akan dikembangkan dalam penelitian ini, maka siswa dapat melihat, meraba, dan memanipulasi alat peraga, yang menghasilkan pengalaman yang nyata dalam kehidupan tentang arti konsep dan prinsip (rumus) khususnya volume balok dan tabung, sehingga siswa dapat belajar bermakna.

\section{METODE}

Penelitian ini merupakan penelitian pengembangan (research and development/ R\&D) karena penelitian ini akan menghasilkan produk alat peraga untuk menemukan prinsip (rumus) volume balok dan tabung. Sesuai dengan pendapat Sugiyono (2008), menyatakan bahwa metode penelitian dan pengembangan atau dalam bahasa Inggrisnya disebut Research and Development adalah metode penelitian yang digunakan untuk menghasilkan produk tertentu, dan menguji keefektifan produk tersebut.

Penelitian ini dilakukan dengan tahapan sebagai berikut

\section{Analisis Kebutuhan}

Pada tahapan ini dilakukan pengumpulan informasi tentang ketidakmampuan guru bidang studi matematika mengembangkan alat peraga dan membimbing siswa mengkonstruksi volume balok dan tabung (seperti diuraikan pada latar belakang.

2. Identifikasi kebutuhan

Berdasarkan Need Analisis, maka dipandang perlu untuk membuat dan mengembangkan alat ukur volum balok dan tabung, dan alat peraga manipulative volume balok dan tabung

\section{Perancangan}

Pada tahap ini dirancang dan dikembangkan alat peraga manipulatif volume balok dan tabung.

4. Validasi Desain

Alat peraga manipulatif volume balok dan tabung berikut panduan penggunaan untuk mengkonstruksi rumus volume balok dan tabung divalidasi oleh pakar pendidikan matematika, yaitu tiga orang dosen program studi pendidikan matematika.

5. Uji coba kelompok kecil

Hasil pengenbangan alat peraga manipulative volume balok dan tabung diuji cobakan pada 5 (lima orang) mahasiswa program studi pendidikan matematika (calon guru matematika).

6. Revisi

Berdasarkan hasil validasi dan uji coba alat peraga dan panduan, dilakukan revisi/ penyempurnaan.

\section{HASIL DAN PEMBAHASAN}

Berdasarkan permasalahan yang diajukan yaitu: 1). Media pembelajaran (Alat peraga) seperti apa yang dapat digunakan untuk pembentukan rumus Volume Balok $=\mathrm{p} 1$ $\mathrm{t}$ dan Volume Tabung $=\pi \mathrm{r}^{2} \mathrm{t}$ ? dan 2). Bagaimana cara pembentukan ( mengkonstruksi ) rumus Volume Balok dan Volume Tabung menggunakan alat peraga ?

Untuk menjawab rumusan masalah yang telah dirumuskan diatas, berikut ini adalah gambar alat peraga dan cara pengunaannya untuk mengkonstruksi prinsip (rumus) volume balok dan tabung (tabung).

Untuk mengukur Volume (besaran yang dibatasi oleh sisi-sisi) balok diperlukan alat ukur. Halnya jika untuk mengukur panjang atau jarak diperlukan alat ukur panjang yang bernama $\mathrm{cm}, \mathrm{dm}, \mathrm{m}, \mathrm{km}$ dan lain-lain sesuai jarak yang akan diukur. Alat ukur volume atau isi diberi nama sesuai alat ukur rusuk, jika rusuk dengan alat ukur $\mathrm{cm}$, maka alat ukur volume adalah $\mathrm{cm}^{3}$, begitu juga jika rusuk dengan $\mathrm{m}$, maka volume dengan $\mathrm{m}^{3}$. Sebuah kubus yang pajang rusuknya $1 \mathrm{~cm}$ mempunyai volume $1 \mathrm{~cm}^{3}$.

Untuk mengukur volume suatu balok yang panjang rusuknya $6 \mathrm{~cm}, 4 \mathrm{~cm}$ dan $5 \mathrm{~cm}$, 
PRINSIP Pendidikan Matematika

Volume 2, Nomor 1, November 2019

digunakan alat ukur kubus satuan yang volumenya $1 \mathrm{~cm}^{3}$. Perhatikan gambar berikut.

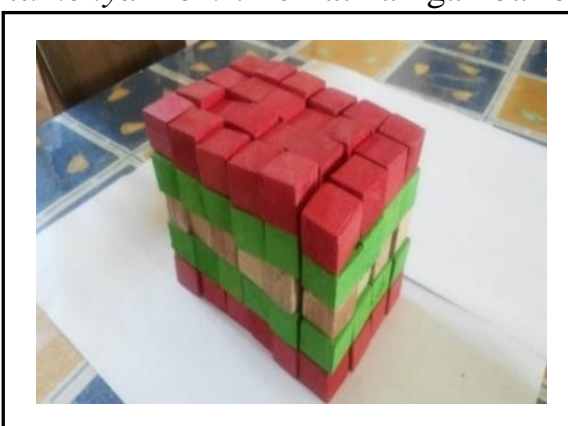

Gambar 1. Balok yang Berukuran $6 \mathrm{~cm}, 4 \mathrm{~cm}$ dan $5 \mathrm{~cm}$ yang Akan diukur Volumenya

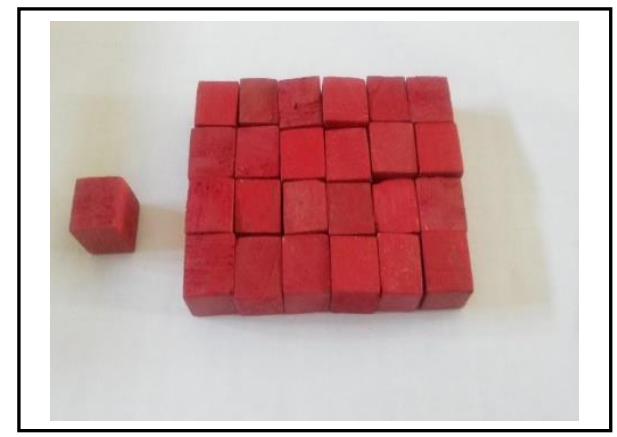

Gambar 2. Balok yang berukuran $6 \mathrm{~cm}, 4 \mathrm{~cm}$, $1 \mathrm{~cm}$

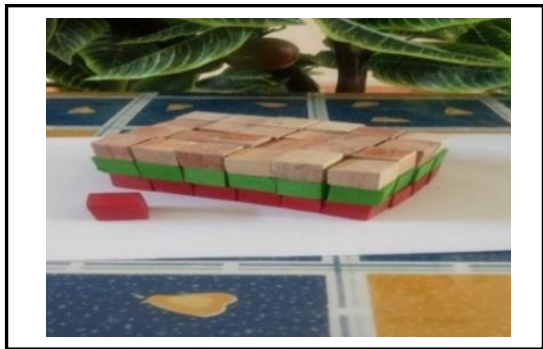

Gambar 3. Balok Berukuran $6 \mathrm{~cm}, 4 \mathrm{~cm}, 3 \mathrm{~cm}$

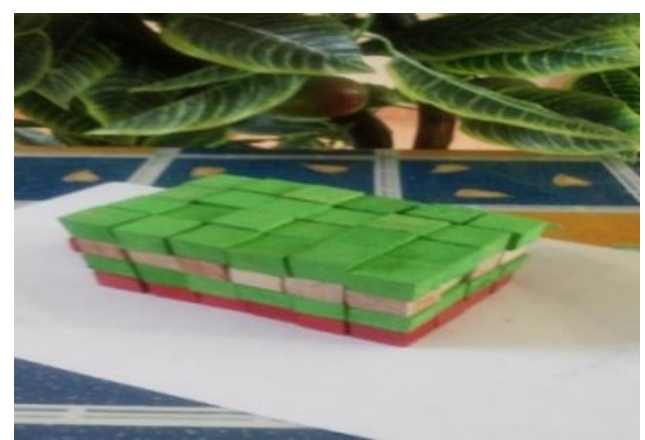

Gambar 4. Penghitungan Volume Balok dengan Kubus Satuan
Prosedur penentuan volume suatu balok yaitu sebagai berikut.

1. Gambar 1 adalah sebuah balok yang berukuran rusuk $6 \mathrm{~cm}, 4 \mathrm{~cm}$ dan $5 \mathrm{~cm}$ yang akan diukur volumenya.

2. Gambar 2 adalah kubus yang mempunyai panjang rusuk $1 \mathrm{~cm}$ dengan volume $1 \mathrm{~cm}^{3}$ dan balok yang berukuran $6 \mathrm{~cm}, 4 \mathrm{~cm}$ dan $1 \mathrm{~cm}$. Dengan menggunakan kubus dengan volume $1 \mathrm{~cm}^{3}$, dapat dihitung volume balok

$\mathrm{V}=6 \mathrm{~cm}^{3}+6 \mathrm{~cm}^{3}+6 \mathrm{~cm}^{3}+6 \mathrm{~cm}^{3}=$ $4 \times 6 \mathrm{~cm}^{3}$

3. Gambar 3 adalah balok yang berukuran 6 $\mathrm{cm}, 4 \mathrm{~cm}$ dan $3 \mathrm{~cm}$, sehingga volume balok adalah $\mathrm{V}=4 \times 6 \mathrm{~cm}^{3}+4 \times 6 \mathrm{~cm}^{3}$ $+4 \times 6 \mathrm{~cm}^{3}=3 \times 4 \times 6 \mathrm{~cm}^{3}$

4. Berdasarkan perhitungan $1,2,3$ dan 4 , maka volume balok pada gambar 1 adalah $\mathrm{V}=5 \times 4 \times 6 \mathrm{~cm}^{3}=4 \times 5 \times 6 \mathrm{~cm}^{3}=6 \times$ $4 \times 5 \mathrm{~cm}^{3}$, sehingga dapat ditarik kesimpulan bahwa volume balok $\mathbf{V}=\mathbf{p} \mathbf{x}$ $\mathbf{l} \mathbf{x}$ t dalam satuan volume yang sesuai dengan satuan pang rusuk

Untuk menentukan volume tabung, dapat dengan cara memanipulasi tabung menjadi balok, dan menggunakan prinsip hukum kekekalan volume ( bahwa volume benda tetap walaupun berubah bentuk). Perhatikan gambar tabung berikut.

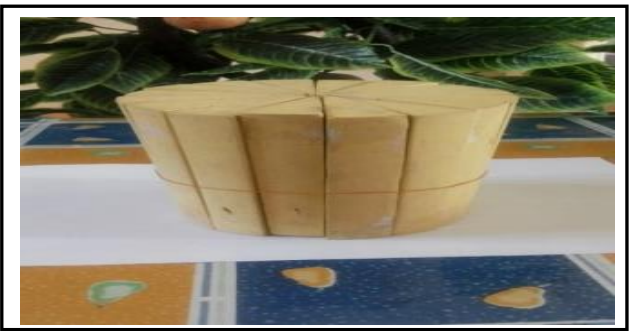

Gambar 5. Tabung Setinggi $1 \mathrm{~cm}$
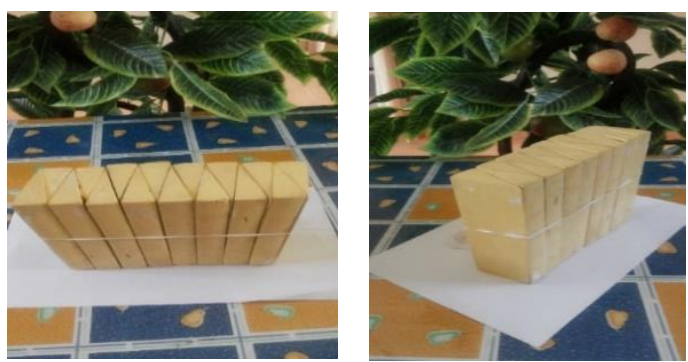

Gambar 6. Manipulasi Tabung Menjadi Menyerupai Balok 
Prosedur penentuan volume tabung yaitu sebagai berikut.

1. Gambar 6 adalah sebuah tabung yang mempunya jari-jari alas $\mathrm{r} \mathrm{cm}$ dan tinggi $\mathrm{t}$ $\mathrm{cm}$ akan dihitung volumenya dan sudah dipotong menjadi 16 bagian sama besar.

2. Gambar 7 adalah manipulasi tabung dari gambar 6 menjadi menyerupai balok. Jika jumlah potongan balok diperbesar ( besar dari 16 ), maka hasil manipulasi akan makin menyerupai balok dengan ukuran rusuk $\pi \mathrm{rm}, \mathrm{r} \mathrm{cm}$ dan $\mathrm{t} \mathrm{cm}$.

3. Sehingga volume tabung $\mathrm{V}_{\text {tabung }}=\pi \mathrm{r}^{2} \mathrm{t}$ $\mathrm{cm}^{3}$

Untuk memberikan penilaian terbadap produk alat peraga untuk mengkonstruksi volume balok dan tabung, terlebih dahulu peneliti mendemonstrasikan prosedur penggunaan alat peraga untuk menemukan formula volume balok dan tabung. Berikut ini adalah hasil penilaian oleh validator.

Tabel 2. Hasil Validasi Alat Peraga Volume Balok dan Tabung

\begin{tabular}{|c|c|c|c|c|c|c|}
\hline \multirow{2}{*}{$\begin{array}{l}\text { Jenis } \\
\text { Validasi }\end{array}$} & \multirow[b]{2}{*}{ Aspek } & \multicolumn{3}{|c|}{ Validator } & \multirow[b]{2}{*}{ Rataan } & \multirow[b]{2}{*}{ Nilai } \\
\hline & & 1 & 2 & 3 & & \\
\hline Konten & $\begin{array}{l}\text { Kesesuaian } \\
\text { dengan } \\
\text { tujuan }\end{array}$ & 4 & 3 & 4 & 3,67 & Valid \\
\hline \multirow{3}{*}{ Muka } & $\begin{array}{l}\text { Kesesuaian } \\
\text { dengan } \\
\text { prinsip }\end{array}$ & 4 & 3 & 4 & 3,67 & Valid \\
\hline & $\begin{array}{l}\text { Cara kerja } \\
\text { (prosedur) }\end{array}$ & 4 & 3 & 4 & 3,67 & Valid \\
\hline & $\begin{array}{l}\text { Mudah } \\
\text { digunakan }\end{array}$ & 4 & 3 & 4 & 3,67 & Valid \\
\hline
\end{tabular}

Berdasarkan penilaian alat peraga oleh validator seperti yang terlihat pada tabel diatas, maka dapat disimpulkan bahwa alat peraga untuk mengkonstruksi formula untuk menghitung volume balok dan tabung adalah valid ditinjau dari isi dan muka.

Matematika mempunyai objek kajian yang abstrak, yaitu fakta, konsep, prinsip dan prosedur. Oleh sebab itu dibutuhkan alat bantu belajar yang kongkrit untuk membantu siswa memahami, dan mampu menggunakannya untuk problem solving.

Untuk membantu guru dan siswa mengkonstruksi volume balok dan tabung secara benar, telah dibuat alat peraga yang dengan alat peraga ini siswa dan guru, melakukan kegiatan Observing (mengamati), Questioning (menanya), Experimenting (mencoba), Assosiating (menalar) dan Konklusing (menyimpulkan). Sumadi (2014) menyatakan bahwa pembelajaran yang mengikuti proses seperti diatas akan mendorong kreativitas siswa sampai $200 \%$.

\section{SIMPULAN}

Berdasarkan hasil penelitian dan pembahasan diatas dapat disimpulkan bahwa alat peraga untuk mengkonstruksi formula volume (isi) balok dan tabung dapat digunakan ( Valid ) pada pendidikan dasar dan menengah.

Oleh sebab itu disarankan pada guruguru matematika pendidikan dasar dan menengah untuk dapat menggunakan alat peraga dalam menyampaikan objek abstrak matematika yang harus difahami oleh siswa, terutama untuk menemukan prinsip seperti formula volume balok dan tabung.

\section{DAFTAR PUSTAKA}

Djamarah, S.B. dan Zain, A. (2002). Strategi Belajar Mengajar. Jakarta: Rineka Cipta.

Hudoyo, H. (1998). Pengembangan Kurikulum Matematika dan Pelaksanaannya di Depan Kelas. Surabaya: Usaha Nasional

Hudoyo, H. (1998). Pembelajaran Matematika Menurut Pandangan Konstruktivistik. Seminar Nasional Upaya-upaya Meningkatkan Peran Pendidikan dalam Era Globalisasi, Malang: 4 April 1998.

Matondang, Z. (2009). Validitas dan Reliabelitas Suatu Intrumen Penelitian. Jurnal Tabularasa Unimed, 6(1), 87 - 97

Munadi. (2012). Media Pembelajaran. Jakarta: Grafindo Pers

Pujiati. (2009a). Pemanfaatan Alat Peraga Sebagai Media PembelajaranMatematika SD. Makalah tidak dipublikasikan. Yogyakarta: PPPPTK

Pujiati. (2009b). Pembuatan Alat Peraga Matematika. Petunjuk Penggunaan AlatPeragaMatematika untuk Guru. Yogyakarta: PPPPTK. 
PRINSIP Pendidikan Matematika

Volume 2, Nomor 1, November 2019

Soedjadi. 2000. Kiat Pendidikan Matematika di Indonesia. Jakarta: Ditjen Dikti Depdiknas.

Sudjana, N. (2004). Penilaian Hasil Proses Belajar Mengajar. Bandung: PT Remaia Rosdakarya

Sugiyono. (2008). Metode Penelitian Kuantitatif, Kualitatif dan $R \& D$, Bandung: Alfabeta
Sumadi, T. (2014). Implementasi Kurikulum 2013. Bahan Presentasi disampaikan pada Sosialisasi Kurikulum FKIP Universitas Riau 2014 dan Lokakarya Implementasi Kurikulum 2013. Pekanbaru. 